\title{
Impact of human papillomavirus infection in semen on sperm progressive motility in infertile men: a systematic review and meta-analysis
}

\author{
Xiaodan Cao*, Renxiong Wei, Xiaoxia Zhang, Jun Zhou, Jiangtao Lou and Yun Cui
}

\begin{abstract}
Background: Human papillomavirus (HPV) has been considered as one of the most common sexually transmitted viruses that may be linked to unexplained infertility in men. The possible mechanisms underlying correlation between HPV infection and infertility could be related to the altered sperm parameters. Current studies have investigated the effect of HPV seminal infection on sperm quality in infertile men, but have shown inconsistent results.

Methods: We systematically searched PubMed, Embase, Web of Science and CNKI for studies that examined the association between HPV seminal infection and sperm progressive motility. Data were pooled using a randomeffects model. Outcomes were the sperm progressive motility rate. Results are expressed as standardised mean difference (SMD) with 95\% confidence interval (Cl). Heterogeneity was evaluated by the I-square $\left(I^{2}\right)$ statistic.

Results: Ten studies were identified, including 616 infertile patients with HPV seminal infection and 2029 infertile controls without HPV seminal infection. Our meta-analysis results indicated that sperm progressive motility was significantly reduced in HPV-infected semen samples compared with non-infected groups [SMD:-0.88, 95\% Cl:-1.17 $\sim-0.59]$. There existed statistical heterogeneity $\left(P^{2}\right.$ value: $\left.86 \%\right)$ and the subgroup analysis suggested that study region might be the causes of heterogeneity.

Conclusions: HPV semen infection could significantly reduce sperm progressive motility in infertile individuals. There were some limitations in the study such as the differences in age, sample sizes and the number of HPV genotypes detected. Further evidences are needed to better elucidate the relationship between HPV seminal infection and sperm quality.
\end{abstract}

Keywords: Human papillomavirus, Male infertility, Sperm quality, Progressive motility, Meta-analysis

\footnotetext{
* Correspondence: cxd0319@163.com

Department of Clinical Laboratory, Ningbo Hospital of Traditional Chinese

Medicine, Affiliated to Zhejiang Chinese Medical University, Ningbo 315000,

China
}

(c) The Author(s). 2020 Open Access This article is licensed under a Creative Commons Attribution 4.0 International License, which permits use, sharing, adaptation, distribution and reproduction in any medium or format, as long as you give appropriate credit to the original author(s) and the source, provide a link to the Creative Commons licence, and indicate if changes were made. The images or other third party material in this article are included in the article's Creative Commons licence, unless indicated otherwise in a credit line to the material. If material is not included in the article's Creative Commons licence and your intended use is not permitted by statutory regulation or exceeds the permitted use, you will need to obtain permission directly from the copyright holder. To view a copy of this licence, visit http://creativecommons.org/licenses/by/4.0/ The Creative Commons Public Domain Dedication waiver (http://creativecommons.org/publicdomain/zero/1.0/) applies to the data made available in this article, unless otherwise stated in a credit line to the data. 


\section{Introduction}

Infertility is defined as the inability of a couple to conceive after 1 year of unprotected sexual intercourse, which affects approximately one-fifth of couples at the reproductive age [1]. Among them, male infertility contributes to roughly $50 \%$ of overall infertility cases [2]. Seminal infections are significant etiologic factors in male infertility and often associated with impaired semen quality $[3,4]$. Chronic viral infection of the urogenital tract, especially human immunodeficiency virus (HIV) infection, may result in urethral inflammation and decreased fertility $[5,6]$. Hepatitis B virus (HBV) and hepatitis $\mathrm{C}$ virus $(\mathrm{HCV})$ infections in semen can also adversely alter seminal parameters $[7,8]$. Human papillomavirus (HPV) is one of the most common sexually transmitted viruses in both males and females worldwide [9]. Some studies have reported that HPV can bind to the head of sperm and result in decreasing male fertility or even causing infertility [10]. A significant association between seminal HPV infection and male fertility abnormality has been reported [11, 12]. Also, recent researches suggested that HPV infection of semen represented a significant risk factor for infertility in men $[13,14]$.

The possible mechanisms underlying correlation between HPV seminal infection and infertility remain unclear [15] and one possibility is that HPV infection significantly lowered the key sperm parameters [14]. Sperm progressive motility has conventionally been considered as a good indicator of motility and a key functional parameter essential for fertilization. The effects of HPV infection on sperm progressive motility in infertile men have been investigated, but the results are controversial [16]. Several researches indicated that HPV infection was closely related to male infertility with decreased sperm progressive motility [17-25], while Zheng et al. revealed that there was no significant difference of sperm progressive motility rate between infected and non-infected infertile subjects [26]. In this research, we performed a systematic review and meta-analysis to investigate the possible impact of HPV infection in semen on sperm progressive motility in infertile individuals.

\section{Methods}

\section{Literature search}

Two independent reviewers searched the PubMed, Embase, Web of Science and CNKI from inception until September 2019. The study type was not restricted. The following search terms were used in combination for search strategies: "human papillomavirus", "HPV", "infertility", "semen", "sperm quality", "sperm parameter" and "progressive motility". We also conducted manual searches of relevant additional references cited in review articles.

\section{Eligibility criteria}

Studies were included if sperm progressive motility could be directly extracted from the original article. Data should be expressed as mean \pm standard deviation (SD). Studies were excluded if they were: 1) reports not focusing on infertile patients or participants with male accessory gland infection; 2) without SD value; 3) case reports or reviews.

The inclusion criteria of infertile patients were at least 1 year of unprotected sexual intercourse without contraception, and healthy female partners (their tubal, uterine, cervical abnormalities, and ovarian disorders were excluded). Exclusion criteria were presence of antisperm antibodies, azoospermia, undescended testis, chromosome abnormalities and history of orchitis, epididymitis, epididymo-orchitis, varicocele and/or sexually transmitted infections in couples [27]. Study populations were separated into two groups: infertile patients with HPV seminal infection and infertile patients without HPV seminal infection. Diagnosed with HPV seminal infection in general population and fertile men were also excluded.

\section{Data extraction and risk of bias}

The data of all included articles were extracted independently by two investigators. Disagreements were discussed and resolved by consensus. Key variables of interest from each study included: first author, publication year, population characteristics (country of region, age, sample size), HPV genotype, sperm progressive motility in infertile patients with or without HPV semen infection.

The Cochrane Handbook for Systematic Reviews was used to assess the risk of bias in each study. The inclusion criteria, risk of bias at the study level and data extraction were evaluated (Supplemental Figure S1 and Supplemental Figure S2). The primary outcome was the rate of sperm progressive motility.

\section{Statistical analysis}

The inputted data included sample sizes and outcome measures with mean and standard deviations. Outcome measures were converted into the SMD with 95\% CI. Heterogeneity was evaluated by $I^{2}$ statistic to quantify the percentage of total variation across studies. If $I^{2}$ value was greater than $50 \%$, the summary estimate was analyzed in a random effect model. Otherwise, a fixed effect model was used. Sensitivity analysis was conducted to estimate whether any single study influenced the stability of the meta-analytic results by sequentially removing individual included study. Publication bias was assessed by Egger's test and statistical analyses were performed using RevMan 5.3 and STATA 16.0. 


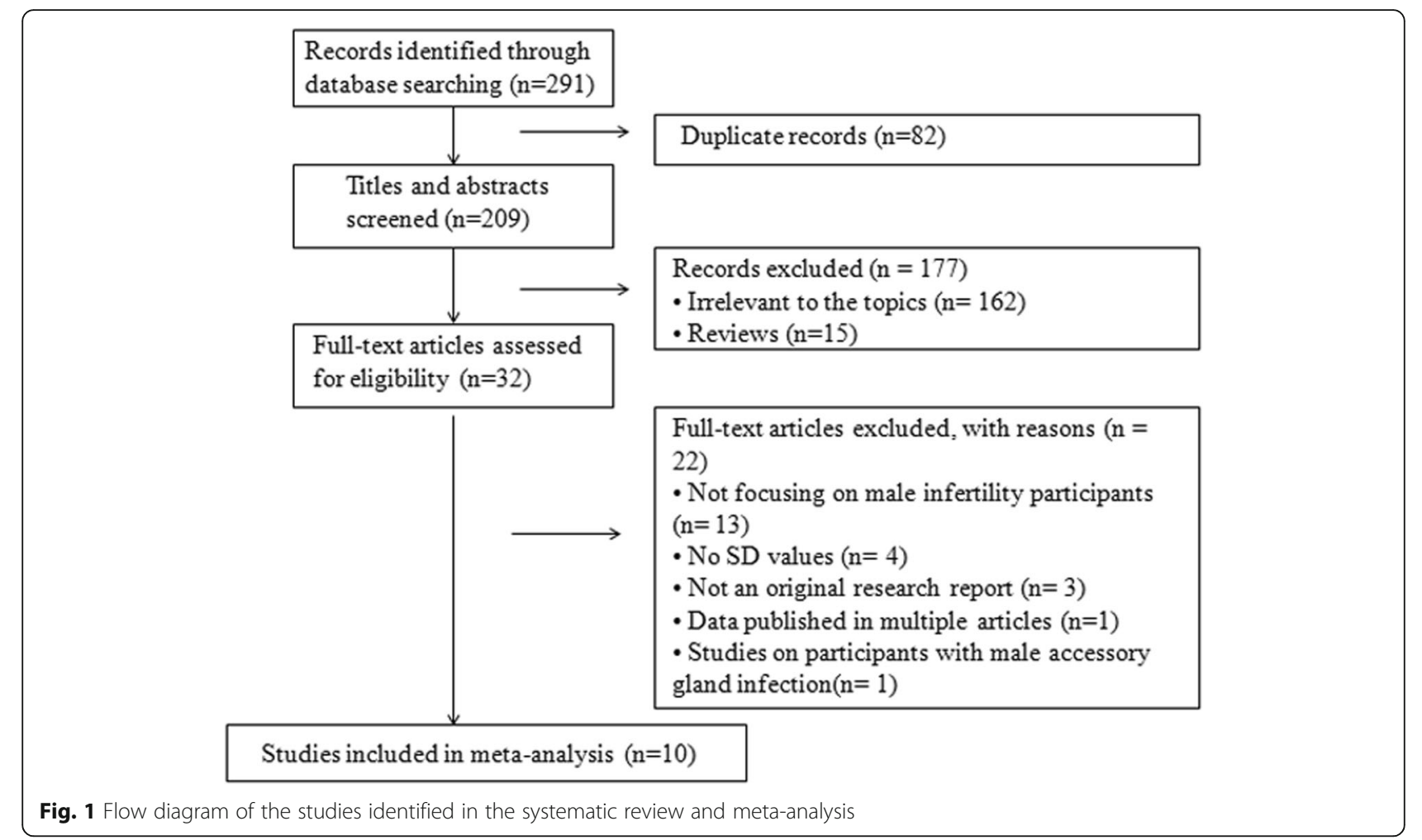

\section{Results}

\section{Study characteristics}

The initial literature search yielded 291 potentially relevant studies. Most ineligible studies were excluded based on information in the title or abstract and the remaining 32 eligible studies were reviewed in detail. The selection process was shown in Fig. 1. As a result, ten articles were included in the final meta-analysis, providing data on 616 HPV DNA positive men among 2645 participants from 3 countries. The main characteristics of the studies included in our meta-analysis were described in Table 1.

\section{Meta analysis}

To assess the effect of HPV seminal infection on sperm progressive motility, ten eligible studies including 616 infertile patients with HPV-infected in semen and 2029 non-infected infertile subjects were analyzed. According

Table 1 Basic characteristics of the eligible studies included in the present meta-analysis

\begin{tabular}{|c|c|c|c|c|c|}
\hline \multirow[t]{2}{*}{ Study } & \multirow[t]{2}{*}{ Country } & \multicolumn{2}{|l|}{ Age /Sample size (n) } & \multirow[t]{2}{*}{ HPV genotype } & \multirow[t]{2}{*}{ Study Design } \\
\hline & & $\mathrm{HPV}+$ patients & HPV-patients & & \\
\hline Moghimi 2019 [20] & Iran & $\mathrm{NA}(n=8)$ & NA $(n=62)$ & $16,18,31,33,35,39,45,51,52,56,58,59$ & Case-control \\
\hline Yang 2016 [24] & China & NA $(n=64)$ & NA $(n=289)$ & 18 HPV genotypes including $16,45,52,59,18,33,68,81$ & Cross-sectional \\
\hline Garolla 2016 [21] & Italy & $\mathrm{NA}(n=54)$ & NA $(n=172)$ & NA & Cross-sectional \\
\hline Foresta 2015 [22] & Italy & $37.1 \pm 7.4(n=179)$ & $38.2 \pm 8.1(n=440)$ & $\begin{array}{l}6,11,16,18,26,31,33,35,39,40,42,43,44,45,51 \\
52,53,54,56,58,59,66,68,69,71,70,73,74\end{array}$ & Cohort \\
\hline Yang 2015 [25] & China & NA $(n=86)$ & NA $(n=41)$ & $6,11,16,18,31,33,45,52,56,58$ & Cross-sectional \\
\hline Zheng 2014 [26] & China & $N A(n=30)$ & NA $(n=300)$ & $6,16,18,31,33,52,58$ & Cross-sectional \\
\hline Foresta 2013 [23] & Italy & $38.8 \pm 9.8(n=16)$ & $37.5 \pm 5.9(n=16)$ & HPV-16 & Cross-sectional \\
\hline Yang 2013 [19] & China & NA $(n=107)$ & NA $(n=508)$ & $\begin{array}{l}\text { At least } 20 \mathrm{HPV} \text { genotypes, including } 6,11,16,18 \text {, } \\
31,33,39,40,42,43,45,51,52,53,54,59,66,68,70,81\end{array}$ & Cross-sectiona \\
\hline Garolla 2013 [17] & Italy & $35.3 \pm 4.7(n=61)$ & $34.2 \pm 3.8(n=104)$ & $\begin{array}{l}6,11,16,18,26,31,33,35,39,40,42,43,44,45,51 \\
52,53,54,56,58,59,66,68,69 / 71,70,73,74,82 .\end{array}$ & Cross-sectiona \\
\hline Foresta 2010 [18] & Italy & $\mathrm{NA}(n=11)$ & NA $(n=97)$ & $6,16,18,52,53,56,61,66,70,84,90$ & Cross-sectional \\
\hline
\end{tabular}


to the results of the heterogeneity test, the random effect model was chosen to estimate the SMD. A significant reduction of sperm progressive motility was found in semen samples of HPV-infected infertile patients compared with non-infected groups (SMD:-0.88, 95\% CI:$1.17 \sim-0.59$ ) (Fig. 2).

A subgroup analysis was performed to differentiate the effect size based on study region. The pooled SMD was highest in China $(-0.59,95 \% \mathrm{CI}:-0.73 \sim-0.45)$, followed by Italy $(-1.10,95 \% \mathrm{CI}:-1.54 \sim-0.67)$ and Iran (-1.26, 95\% CI: $-2.02 \sim-0.49)$ (Fig. 3). There was no statistical heterogeneity in the subgroup of China.

\section{Sensitivity analysis}

None of an individual study significantly altered the overall significance of the combined SMD in the analyses relating to the impact of HPV seminal infection on sperm progressive motility in infertile individuals (Fig. 4).

\section{Publication bias}

Egger's test of publication bias of the seminal HPV infection on sperm progressive motility in infertile patients indicated a lack of publication bias $(P=0.84)$.

\section{Discussion}

HPV has been considered as an infectious factor that might be linked to unexplained infertility in men. Previous meta analyses have reported the prevalence of HPV in semen [28] and the risk for male infertility [13, 14]. Laprise et al. [28] exhibited that the pooled HPV prevalence in semen was estimated at $16 \%$ for men seeking fertility evaluation/treatment and at $10 \%$ in general populations. Xiong et al. [14] and Lyu et al. [13] demonstrated that HPV semen infection was a risk factor for male fertility abnormality with an OR of 3.02 (95\% CI: 2.11-4.32) and 2.93 (95\% CI: 2.03-4.24) respectively. The issue whether HPV seminal infection has significance and consequence for sperm progressive motility in infertile men is controversial. The current study conducted a meta-analysis to evaluate the impact of HPV semen infection on sperm progressive motility in infertile subjects. The results showed that the prevalence of HPV detection in semen in infertile men ranged from $9.1 \%$ by Zheng et al. [26] to $67.7 \%$ by Yang et al. [25]. Sperm progressive motility reduced significantly in seminal HPV infected patients compared with non-infected groups. In the aspect of HPV genotypes distribution, the results showed that HPV-16, HPV-18/52, HPV-33, in decreasing order, were the most prevalent genotypes in semen of infertile group. Previous studies have shown that in semen the HPV were detected both in exfoliated cells [29] and in sperm surface, especially in the sperm head [17]. In an in vitro study, Carlo et al. [30] reported that HPV could infect human sperm and it localized at the equatorial region of sperm head through interaction between the HPV capsid protein L1 and syndecan-1. Moreover, HPV binding to sperm was tenacious [10, 31] and conventional methods of sperm washing could not clear HPV DNA from sperm surface [32].

The pathogenic mechanism explicating the reduction of sperm progressive motility related to seminal HPV infection might be associated with anti-sperm antibodies (ASAs), glandular dysfunction and sperm DNA fragmentation. Firstly, several studies have shown that infertile patients with HPV semen infection had a high percentage of ASAs on sperm surface and the presence of HPV in semen was frequently related with ASAs of IgA and IgG classes, which suggested that the presence of HPV DNA on the sperm surface might represent an antigenic stimulus for ASA formation [17, 33]. Although the role of ASAs is controversial, some mechanisms have been proposed affecting sperm quality: sperm agglutination and complement mediated sperm cytotoxicity occurring within the male genital tract [34]. Secondly, HPV seminal infection in infertility men may have altered proportions of secretory products mainly from prostate and seminal vesicles, which could have a negative impact on

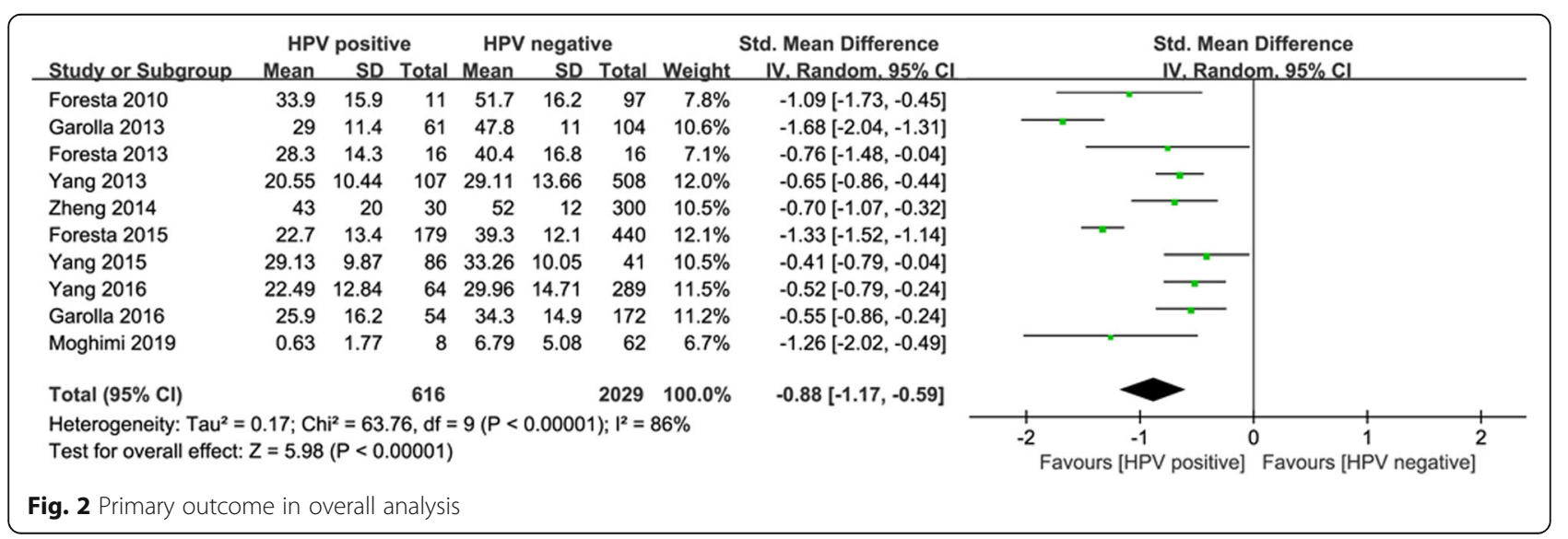




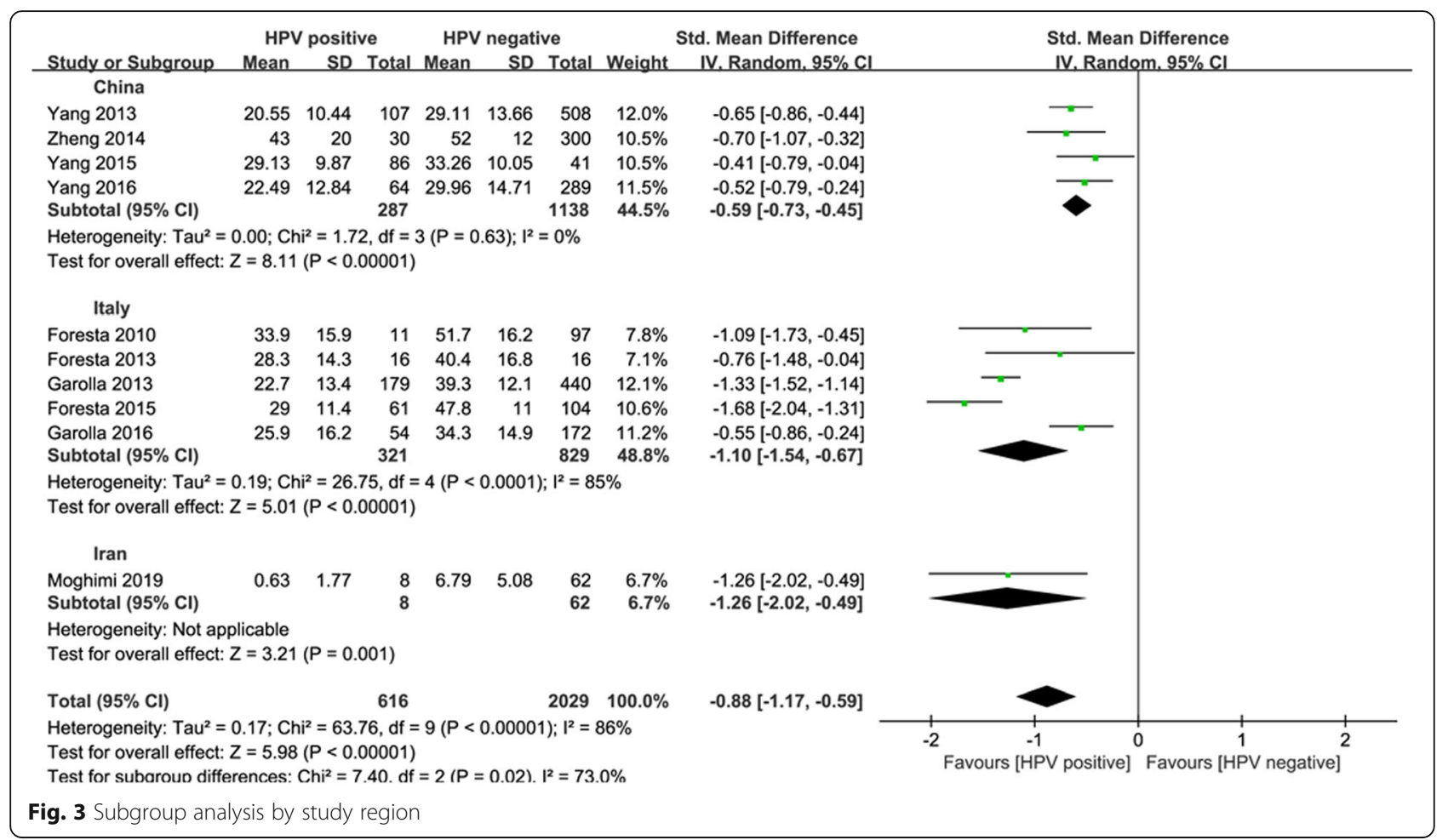

sperm motility [35]. Thirdly, HPV infection might result in the increased rate of sperm DNA fragmentation and apoptosis. In vitro study by Connelly et al. [36] indicated that sperm cells transfected with exogenous HPV E6/E7 DNA had higher percentages of breakages characteristic of apoptosis compared to the uninfected controls. In contrary, in vivo study by Cortes et al. [37] failed to find any association between HPV positive and sperm DNA fragmentation. Further evidence gathered through well-designed trials to confirm whether HPV-infected sperm is more susceptible to DNA damage is warranted.

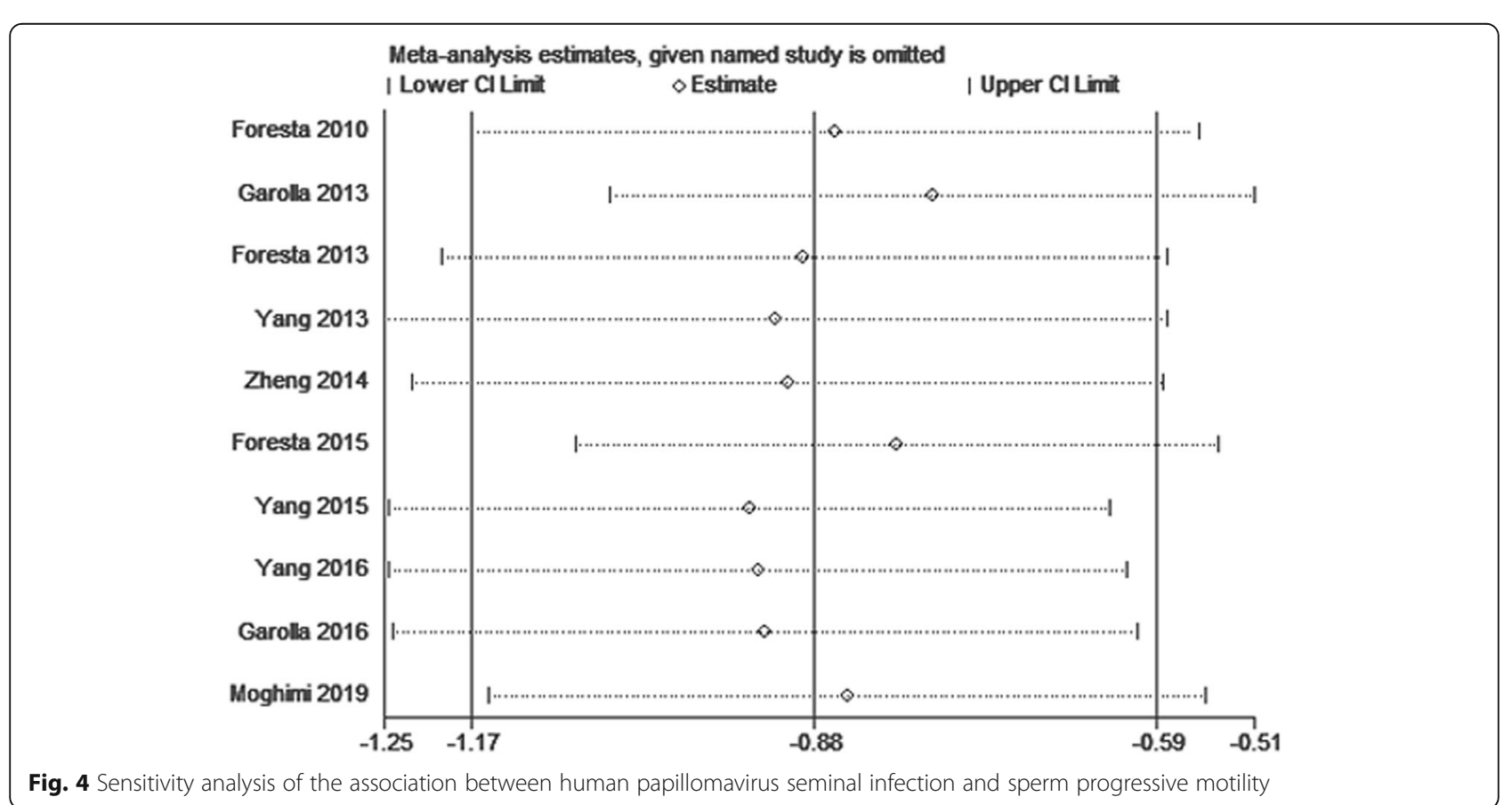


In fact, HPV-infected sperm maintained their ability to fertilize the oocyte, interfered with implantation and embryo development, thus affecting the outcome and safety of assisted reproduction techniques (ARTs) [38]. Henneberg et al. [39] demonstrated embryo stage-specific disruption effects of HPV on early development. Perino et al. [40] reported the lower pregnancy rate and increased percentage of abortions in ARTs with HPV positive in semen. In a cross-sectional clinical study [21], cumulative pregnancy rates recorded in noninfected and infected couples undergoing ART were, respectively, 38.4 and $14.2 \%$. During the follow-up of these pregnancies, a significantly higher miscarriage rate $(62.5 \%$ vs. $16.7 \%$ of noninfected) was observed in HPV-infected subjects. In particular, all pregnancy losses of the infected group took place very early (three at 5 th and two at 6 th gestational week).

The results showed that $I^{2}$-value was greater than $50 \%$, which suggested that there was potential heterogeneity between studies. The heterogeneity might be attributed to differences in study region, sample size, the definition of male infertility and the number of HPV types detected. The inclusion criterion of the infertile group was at least 1 year or 2 years of unprotected sexual intercourse without conception. The study by Foresta et al. [23] included the infertile patients of case group only affected by HPV-16 semen infection and HPV-genotypes other than HPV-16 were all excluded. Multiple HPVgenotypes were detected in most of articles included in the present study and the genotype was not mentioned in one study [21]. The results of subgroup analysis showed that $I^{2}$-value was equal to zero in the subgroup of China, which suggested that study region might be the causes of heterogeneity.

In addition, some limitations of the present metaanalysis should be considered when interpreting the results. Firstly, though we performed an extensive literature search, potential selection bias could not be completely avoided because only articles published in Chinese and English were included. Secondly, some important confounding factors, such as male age and environmental exposures were not always noted. These factors might have confounding effects on the correlation between HPV semen infection and reduced sperm progressive motility. Thirdly, most articles were not prospective study and might therefore decrease the reliability of our results.

\section{Conclusions}

In summary, the current evidences suggest that HPV semen infection could significantly reduce sperm progressive motility in infertile individuals compared with non-infected infertile group. This information could make recommendations for reproduction diagnosis and treatment and could affect public health. However, this evidence is far from conclusive because of the small sample sizes and existing confounding factors of the currently available studies. Future studies with large sample size and rigorous design are necessary to elucidate the impact of HPV semen infection on sperm quality.

\section{Supplementary information}

Supplementary information accompanies this paper at https://doi.org/10. 1186/s12958-020-00604-0.

Additional file 1: Figure S1. Assessment of risk of bias.

Additional file 2: Figure S2. Assessment of risk of bias.

\section{Abbreviations}

ARTs: Assisted reproduction techniques; ASAs: Anti-sperm antibodies; Cl: Confidence interval; HBV: Hepatitis B virus; HCV: Hepatitis C virus; HIV: Human immunodeficiency virus; HPV: Human papillomavirus; SD: Standard deviation; SMD: Standardised mean difference

\section{Acknowledgements}

None.

Ethical approval and consent to participate Not applicable.

\section{Authors' contributions}

XC and RW conceived and designed the study. XZ and JZ performed the systematic literature review. XC and $J \mathrm{~L}$ conducted the statistical analysis. XC and $Y C$ drafted the manuscript. All authors reviewed and approved the final version of the manuscript.

Funding

This study was supported by Natural Science Foundation of Ningbo (2018A610330; 2019A610357).

Availability of data and materials

The current study was based on results of relevant published studies.

Consent for publication

Not applicable.

Competing interests

The authors declare that they have no competing interests.

Received: 30 March 2020 Accepted: 27 April 2020

Published online: 07 May 2020

\section{References}

1. Szkodziak P, Wozniak S, Czuczwar P, Wozniakowska E, Milart P, Mroczkowski $A$, et al. Infertility in the light of new scientific reports - focus on male factor. Ann Agric Environ Med. 2016;23(2):227-30.

2. Agarwal A, Mulgund A, Hamada A, Chyatte MR. A unique view on male infertility around the globe. Reprod Biol Endocrinol. 2015;13:37.

3. Rusz A, Pilatz A, Wagenlehner F, Linn T, Diemer T, Schuppe HC, et al. Influence of urogenital infections and inflammation on semen quality and male fertility. World J Urol. 2012;30(1):23-30.

4. Ochsendorf FR. Sexually transmitted infections: impact on male fertility. Andrologia. 2008;40(2):72-5.

5. Kehl S, Weigel M, Muller D, Gentili M, Hornemann A, Sutterlin M. HIVinfection and modern antiretroviral therapy impair sperm quality. Arch Gynecol Obstet. 2011;284(1):229-33.

6. Bujan L, Sergerie M, Moinard N, Martinet S, Porte L, Massip P, et al. Decreased semen volume and spermatozoa motility in HIV-1-infected patients under antiretroviral treatment. J Androl. 2007;28(3):444-52. 
7. Safarinejad MR, Kolahi AA, Iravani S. Evaluation of semen variables, sperm chromosomal abnormalities and reproductive endocrine profile in patients with chronic hepatitis C. BJU Int. 2010;105(1):79-86.

8. Zhou XL, Sun PN, Huang TH, Xie QD, Kang XJ, Liu LM. Effects of hepatitis B virus $S$ protein on human sperm function. Hum Reprod. 2009;24(7):1575-83.

9. Ventimiglia E, Horenblas S, Muneer A, Salonia A. Human papillomavirus infection and vaccination in males. Eur Urol Focus. 2016;2(4):355-62.

10. Foresta C, Garolla A, Zuccarello D, Pizzol D, Moretti A, Barzon L, et al. Human papillomavirus found in sperm head of young adult males affects the progressive motility. Fertil Steril. 2010;93(3):802-6.

11. Souho T, Benlemlih M, Bennani B. Human papillomavirus infection and fertility alteration: a systematic review. PLoS One. 2015;10(5):e0126936.

12. Fode M, Fusco F, Lipshultz L, Weidner W. Sexually transmitted disease and male infertility: a systematic review. Eur Urol Focus. 2016;2(4):383-93.

13. Lyu Z, Feng X, Li N, Zhao W, Wei L, Chen Y, et al. Human papillomavirus in semen and the risk for male infertility: a systematic review and metaanalysis. BMC Infect Dis. 2017;17(1):714.

14. Xiong YQ, Chen YX, Cheng MJ, He WQ, Chen Q. The risk of human papillomavirus infection for male fertility abnormality: a meta-analysis. Asian J Androl. 2018;20(5):493-7.

15. Schuppe HC, Pilatz A, Hossain H, Diemer T, Wagenlehner F, Weidner W. Urogenital infection as a risk factor for male infertility. Dtsch Arztebl Int. 2017;114(19):339-46.

16. Foresta C, Noventa M, De Toni L, Gizzo S, Garolla A. HPV-DNA sperm infection and infertility: from a systematic literature review to a possible clinical management proposal. Andrology. 2015;3(2):163-73.

17. Garolla A, Pizzol D, Bertoldo A, De Toni L, Barzon L, Foresta C. Association, prevalence, and clearance of human papillomavirus and antisperm antibodies in infected semen samples from infertile patients. Fertil Steril. 2013;99(1):125-31.

18. Foresta C, Pizzol D, Moretti A, Barzon L, Palu G, Garolla A. Clinical and prognostic significance of human papillomavirus DNA in the sperm or exfoliated cells of infertile patients and subjects with risk factors. Fertil Steril. 2010;94(5):1723-7.

19. Yang Y, Jia CW, Ma YM, Zhou LY, Wang SY. Correlation between HPV sperm infection and male infertility. Asian J Androl. 2013;15(4):529-32.

20. Moghimi M, Zabihi-Mahmoodabadi S, Kheirkhah-Vakilabad A, Kargar Z. Significant correlation between high-risk HPV DNA in semen and impairment of sperm quality in infertile men. Int J Fertil Steril. 2019;12(4): 306-9.

21. Garolla A, Engl B, Pizzol D, Ghezzi M, Bertoldo A, Bottacin A, et al. Spontaneous fertility and in vitro fertilization outcome: new evidence of human papillomavirus sperm infection. Fertil Steril. 2016;105(1):65-72 e1.

22. Foresta C, Garolla A, Parisi S, Ghezzi M, Bertoldo A, Di Nisio A, et al. HPV prophylactic vaccination in males improves the clearance of semen infection. EBioMedicine. 2015;2(10):1487-93.

23. Foresta C, Bertoldo A, Garolla A, Pizzol D, Mason S, Lenzi A, et al. Human papillomavirus proteins are found in peripheral blood and semen $\mathrm{Cd} 20+$ and Cd56+ cells during HPV-16 semen infection. BMC Infect Dis. 2013;13:593.

24. Yang Y, Li Y, Liang Y, Lan Y. Effect of male HPV infection on semen parameter. Chin J Birth Health Heredity. 2016;24(6):113-4.

25. Yang $X$, Zhang $Y$, Wang $X$. Retrospective analysis of association between human papilloma virus infection and antisperm antibodies in male infertile patients in Xinjiang area. Int J Lab Med. 2015;36(13):1910-2.

26. Zheng $H$, Wang $L$, Chen $X$. The effect of human papillomavirus on sperm motility and sperm chromatin integrity in semen. Chin J Clin (Electronic Edition). 2014;8(1):70-4

27. Banyra O, Nikitin O, Ventskivska I. Acute epididymo-orchitis: relevance of local classification and partner's follow-up. Cent European J Urol. 2019;72(3): 324-9.

28. Laprise C, Trottier H, Monnier P, Coutlee F, Mayrand MH. Prevalence of human papillomaviruses in semen: a systematic review and meta-analysis. Hum Reprod. 2014;29(4):640-51.

29. Lai YM, Lee JF, Huang HY, Soong YK, Yang FP, Pao CC. The effect of human papillomavirus infection on sperm cell motility. Fertil Steril. 1997;67(6):1152-5.

30. Foresta C, Patassini C, Bertoldo A, Menegazzo M, Francavilla F, Barzon L, et al. Mechanism of human papillomavirus binding to human spermatozoa and fertilizing ability of infected spermatozoa. PLoS One. 2011;6(3):e15036.

31. Garolla A, Lenzi A, Palu G, Pizzol D, Bertoldo A, De Toni L, et al. Human papillomavirus sperm infection and assisted reproduction: a dangerous hazard with a possible safe solution. Hum Reprod. 2012;27(4):967-73.
32. Foresta C, Pizzol D, Bertoldo A, Menegazzo M, Barzon L, Garolla A. Semen washing procedures do not eliminate human papilloma virus sperm infection in infertile patients. Fertil Steril. 2011;96(5):1077-82.

33. Zini A, Lefebvre J, Kornitzer G, Bissonnette F, Kadoch IJ, Dean N, et al. Antisperm antibody levels are not related to fertilization or pregnancy rates after IVF or IVF/ICSI. J Reprod Immunol. 2011;88(1):80-4.

34. Francavilla F, Santucci R, Barbonetti A, Francavilla S. Naturally-occurring antisperm antibodies in men: interference with fertility and clinical implications. An update. Front Biosci. 2007;122:890-911.

35. Damke E, Kurscheidt FA, Balani VA, Takeda Kl, Irie MMT, Gimenes F, et al. Male Partners of Infertile Couples with seminal infections of human papillomavirus have impaired fertility parameters. Biomed Res Int. 2017; 2017:4684629.

36. Connelly DA, Chan PJ, Patton WC, King A. Human sperm deoxyribonucleic acid fragmentation by specific types of papillomavirus. Am J Obstet Gynecol. 2001;184(6):1068-70.

37. Cortes-Gutierrez El, Davila-Rodriguez MI, Fernandez JL, de la O-Pérez LO, Garza-Flores ME, Eguren-Garza R, et al. The presence of human papillomavirus in semen does not affect the integrity of sperm DNA. Andrologia. 2017;49:10

38. Pereira N, Kucharczyk KM, Estes JL, Gerber RS, Lekovich JP, Elias RT, et al. Human papillomavirus infection, infertility, and assisted reproductive outcomes. J Pathog. 2015;2015:578423.

39. Henneberg AA, Patton WC, Jacobson JD, Chan PJ. Human papilloma virus DNA exposure and embryo survival is stage-specific. J Assist Reprod Genet. 2006:23(6):255-9.

40. Perino A, Giovannelli L, Schillaci R, Ruvolo G, Fiorentino FP, Alimondi P, et al. Human papillomavirus infection in couples undergoing in vitro fertilization procedures: impact on reproductive outcomes. Fertil Steril. 2011;95(5):1845-8.

\section{Publisher's Note}

Springer Nature remains neutral with regard to jurisdictional claims in published maps and institutional affiliations.
Ready to submit your research? Choose BMC and benefit from:

- fast, convenient online submission

- thorough peer review by experienced researchers in your field

- rapid publication on acceptance

- support for research data, including large and complex data types

- gold Open Access which fosters wider collaboration and increased citations

- maximum visibility for your research: over $100 \mathrm{M}$ website views per year

At BMC, research is always in progress.

Learn more biomedcentral.com/submissions 